ISSN 1981-416X

Licenciado sob uma Licença Creative Commons

\title{
O logos freireano: os paradoxos da palavra que quebra o silêncio e liberta
}

\author{
The freirean logos: the paradoxes of the word \\ that breaks the silence and frees
}

\section{El logos freireano: las paradojas de la palabra que rompe el silencio y libera}

\section{Peri Mesquidaa ${ }^{[a]}$ Abdeljalil Akkari ${ }^{[b]^{*}}$}

[a] Pontifícia Universidade Católica do Paraná (PUCPR), Curitiba, PR, Brasil

[b] Université de Genève, Genève, Suíça

\section{Resumo}

Por quase cinco séculos, a maioria das descobertas científicas e tecnológicas foi feita em países europeus ou sob controle europeu. Mas, esta supremacia, que tem sido de curta duração quando se leva em conta a história humana, ocorreu no contexto das relações coloniais dominantes entre a Europa e o resto do mundo. A supremacia europeia na produção de conhecimento foi, no entanto, enfraquecida pela descolonização e pelo inacabado movimento de minorias culturais pela igualdade. No campo da educação e da pedagogia, Paulo Freire deu uma contribuição fundamental. Por isso mesmo, nenhum livro sobre educação naquele que chamamos Mundo da Maioria pode deixar de se referir à obra de Paulo Freire, seja assumindo seu pensamento filosófico, social e pedagógico, seja criticando. Tanto o autor da 
Pedagogia do oprimido, quanto sua equipe estiveram no centro de muitas discussões pedagógicas em todo o mundo. A interpretação de seu legado varia de acordo com o contexto em que ocorre. Na Europa, Freire é mais conhecido por seu método de alfabetização de adultos. Nos EUA, os teóricos críticos da sociologia e da educação usaram vários conceitos freirianos para abordar as desigualdades educacionais (APPLE, 1996; GIROUX, 1997; MCLAREN, 1997). Na América Latina e em outros países do Terceiro Mundo, o principal ponto de interesse está centrado no valor sócio-político da pedagogia de Freire (LOIOLA e BORGES, 1996; NÓVOA, 1996). Pretendemos neste artigo discutir sobre os aspectos da teoria de Freire que estiveram presentes, ou podem se fazer presentes nas reformas educacionais no Mundo da Maioria. Em algumas seções deste artigo mostraremos os paradoxos da palavra que silencia e da palavra que quebra o silêncio. Em primeiro lugar, argumentamos que os estudiosos da educação comparada não entenderam com clareza a teoria da educação de Freire para diferenciar escolaridade e educação. Na segunda seção, examinamos as ideias de Freire na prática. Examinamos o poder da abordagem de alfabetização freireana, na terceira seção e, na quarta, concluímos com a sugestão de algumas proposições para construir uma educação crítica baseada na herança pedagógica de Freire.

Palavras-chave: Pedagogia freireana. Paradoxos. Educação. Mundo da maioria.

\section{Abstract}

For nearly five centuries, most of the scientific and technological breakthroughs were made in European countries or under European control. But this supremacy, which has been short-lived when human history is taken into account, occurred in the context of the dominant colonial relations between Europe and the rest of the world. European supremacy in the production of knowledge was, however, weakened by decolonization and the unfinished movement of cultural minorities for equality. In the field of education and pedagogy, Paulo Freire made a fundamental contribution. For this reason, no book on education in what we call World of Majority cannot refer to the work of Paulo Freire, be it taking its philosophical, social and pedagogical thinking or criticizing it. Writing about Paulo Freire is difficult challenge. Both the author and his theory have been at the center of many pedagogical discussions around the world. Interpretation of his legacy varies according 
to the context in which it takes place. In Europe, Freire is better known for his method of literacy training used in adult education. In the United States, critical theorists have used several Freirian concepts to address educational inequalities (APPLE, 1996; GIROUX, 1997; MCLAREN, 1997). In Latin America and other Third World countries, the main point of interest centers around the socio-political value of Freire's pedagogy (LOIOLA and BORGES, 1996; NÓVOA, 1996). The goals of this paper are to explore aspects of Freire's theory that might inform educational reforms in the Majority World. In some sections of this paper, we will show the paradoxes of the word that silences and the word that breaks the silence. In the first section, we argue that scholars of comparative education did not understand the Freire's theory in order to differentiate between schooling and education. In the second section, we look at Freire's ideas in practice. We examine the power of Freire's approach to literacy in the third section. In the fourth section, we conclude by suggesting some propositions to build a critical education based on Freire's pedagogical heritage.

Keywords: Freirean pedagogy. Paradoxes. Education. Majority world.

\section{Resumen}

Durante casi cinco siglos, la mayoría de los descubrimientos científicos y tecnológicos se hicieron en países europeos o bajo control europeo. Pero esta supremacía, que ha sido de corta duración cuando se tiene en cuenta la historia humana, ocurrió en el contexto de las relaciones coloniales dominantes entre Europa y el resto del mundo. La supremacía europea en la producción de conocimiento fue, sin embargo, debilitada por la descolonización y el continuado movimiento de minorías culturales por la igualdad. En el campo de la educación y la pedagogía, Paulo Freire dio una contribución fundamental. Por eso mismo, ningún libro sobre educación en el que llamamos Mundo de la Mayoría, puede dejar de referirse a la obra de Paulo Freire, sea asumiendo su pensamiento filosófico, social y pedagógico, sea criticando. Tanto el autor de la Pedagogía del oprimido, como su equipo estuvieron en el centro de muchas discusiones pedagógicas en todo el mundo. La interpretación de su legado varía de acuerdo con el contexto en que ocurre. En Europa, Freire es más conocido por su método de alfabetización de adultos. En los Estados Unidos, los teóricos críticos de la sociología y la educación, utilizaron varios conceptos freireanos 
para abordar las desigualdades educativas (Apple, 1996, Giroux, 1997, McLaren, 1997). En América Latina y en otros países del Mundo de la Mayoría, el principal punto de interés está centrado en el valor socio-político de la pedagogía de Freire (Loiola y Borges, 1996; Nóvoa, 1996). Pretendemos en este artículo discutir sobre los aspectos de la teoría de Freire que estuvieron presentes, o pueden hacerse presentes en las reformas educativas en el Mundo de la Mayoría. En algunas secciones de este artículo colocaremos en destaque de forma más contundente las paradojas de la palabra que silencia y de la palabra que rompe el silencio. En primer lugar, argumentamos que los estudiosos de la educación comparada no entendieron con claridad la teoría de la educación de Freire para diferenciar la escolaridad y la educación. En la segunda sección, examinamos las ideas de Freire en la práctica y su pedagogia de la palabra. Examinamos el poder del enfoque de alfabetización freireana, en la tercera sección y, en la cuarta seccción, concluimos sugiriendo algunas proposiciones para construir una educación crítica basada en la herencia pedagógica de Freire.

Palabras clave: Pedagogía freireana. Paradojas. Educación. Mundo de la mayoría.

\section{Paulo Freire e os paradoxos da educação e da escolarização}

Para desenvolver uma discussão sobre os oprimidos, faz-se necessário situar a escola em um contexto sociocultural mais amplo, pois, como observa Dardar (1991), na medida em que aceitamos as tradicionais relações entre a escola e a sociedade, compactuamos com a iniquidade do sistema educacional. Nesta visão, as escolas são vistas como aparelhos neutros e apolíticos cujo único propósito é dotar os (as) estudantes do conhecimento necessário para que exerçam uma função na sociedade, preparando para o mercado de trabalho. A visão freireana da educação segue um caminho diferente e muito mais radical do que o pensamento dominante sobre o papel da escola. Freire defende a ideia de que a relação entre educação e libertação é não somente complexa como também dialética. Por isso ele acredita que quanto mais qualificado for o sistema educacional para moldar a estrutura da sociedade é, na realidade a sociedade que molda a educação de acordo com os interesses daqueles que exercem 
o poder (FREIRE, 1976). Em outras palavras, não se pode esperar da educação formal tradicional qualquer mudança social positiva, pois ela atua como um instrumento de reforço e reprodução da estrutura de classes do sistema capitalista de produção.

Para colocar em xeque esta posição tradicional (consevadora) contraditória em uma sociedade desigual, é necessária uma educação libertadora. Por isso, Freire propõe uma filosofia da educação baseada em uma síntese do materialismo histórico e dialético, com ênfase na filosofia social e política de Marx e Gramsci, e o pensamento existencialista cristão, com acento especial nas ideias de Emmanuel Mounier e Gabriel Marcel (FREIRE, 1967). No início da década de 1960, o Movimento de Ação Popular exerceu grande influência sobre Freire ao sustentar que as pessoas ao tomarem consciência da realidade na qual vivem, podem realizar uma crítica desta realidade, e se preparar para produzir transformações sociais e políticas. Por isso, a posição de Freire vai no sentido de uma teoria da educação inicialmente heterogênea, que tende a evoluir na medida em que o materialismo histórico e dialético passa a assumir um lugar especial no pensamento freireano, mas sem que ele defenda uma revolução no sentido tradicional do termo. A conscientização é humanista e, por isso mesmo, capaz de levar a mudanças radicais na sociedade (FREIRE, 1993, p. 65-68):

Os homens são porque estão em situação. E serão tanto mais quanto não só pensem criticamente sobre sua forma de estar, mas criticamente atuem sobre a situação em que estão... Daí que da imersão em que se achavam, emergem, capacitando-se para inserir-se na realidade que vai se desvelando. Desta maneira, a inserção é um estado maior que a emersão e resulta da conscientização da situação. É a própria consciência histórica [...] Para alcançar a meta da humanização, que não se consegue sem o desaparecimento da opressão desumanizante, é imprescindível a superação das "situações-limites", em que os homens e as mulheres se acham quase coisificados. 
Paulo Freire examinou as contradições observando as relações entre educadores (as) e estudantes, animadores (as) culturais. Simplificando, a educação formal escolar se processa tendo o professor como centro da ação educativa, aquele que conhece, enquanto o educando nada sabe. O (a) professor (a) é o (a) transmissor (a) do conhecimento para o (a) educando (a) que recebe este conhecimento e o apreende do mestre guardião do saber, negando assim a capacidade ontológica e epistemológica do (a) educando (a) e a comunidade dos (as) educandos (as), de produzirem conhecimento. Trata-se de uma prática pedagógica autoritária e "bancária" de negação dos (das) educandos (as), silenciando-os (as), impedindo que eles (elas) sejam autores (as) da "sua própria história" (FREIRE; et al 1997).

Dessa maneira, a filosofia pedagógica da educação de Freire se opõe à educação bancária como uma forma de ensino tradicional, conservador do status quo, na qual os (as) estudantes supostamente "digerem" o conhecimento e as informações sem qualquer referência ao seu contexto sociopolítico, quando para Freire a educação não é neutra, mas essencialmente política. Assim, aprender a controlar e a exercer o poder não é um objetivo meramente individual, mas um ato coletivo de empoderamento, como dizia Gramsci, com outras palavras (GRAMSCI, 1975, p. 912-945):

Perché si è disgregato l'apparato egemonico del grupo dominante? Forsi perchè si è sviluppata una forte volontá politica collectiva antagônica...un grupo sociale puó e anzi deve essere dirigente gia prima di conquisatare il potere governativo(è questa una dele condizioni principal per la stessa conquista del potere) dopo, quando esercita il potere e anche se lo tiene fortemente in pugno, diventa dominante ma deve continuare ad essere 'dirigente.

Portanto, o poder da comunidade é compartilhado, pois não se trata do poder de alguns indivíduos dominantes que se afirmam às expensas dos outros, mas o poder de um grupo que tem sua força em uma "vontade coletiva" e um propósito numa visão de mundo comum. Ao invés de indivíduos que agem de forma desconexa recebendo o conhecimento no 
vácuo, Freire afirma o aprendizado coletivo no contexto de uma comunidade histórica e geograficamente localizada: "ninguém educa ninguém, ninguém educa a si mesmo, os homens se educam entre si" (FREIRE, 1993, p. 95).

O’ Cadiz, Linquist Wong e Torres (1996), observam, a nosso ver corretamente, que apesar da sua fama e da difusão global da sua revolucionária filosofia da educação, até 1989, quando iniciou sua gestão como Secretário de Educação do Município de São Paulo, Freire não tivera a oportunidade de colocar em prática suas ideias pedagógicas em escolas públicas, portanto no sistema formal de ensino. O interesse tardio de Freire pela educação formal limitou sua influência nos movimentos de reformas educacionais no Brasil, como a própria Lei 9394/96, as Bases Curriculares Nacionais, as Diretrizes, etc., que preferiram tomar aportes em particular na obra de Piaget e autores que seguem as concepções positivistas do psicólogo suíço ${ }^{1}$.

Na realidade, embora Freire tenha falado sobre escola pública e educação popular, ele não chegou a desenvolver uma abordagem conceitual sobre o tema. Vejamos dois exemplos de como Paulo Freire comenta sua ação à frente da Secretaria Municipal de Educação de São Paulo:

A qualidade da escola pública universal não é medida somente pela quantidade de conhecimento transmitido, mas também pela solidariedade de classe que precisa ser construída e pelas oportunidades que os membros da comunidade escolar, incluindo os pais e a comunidade externa, têm de usar a escola como um espaço para a expressão da sua cultura (FREIRE, 1991, p. 15-16).

Na mesma obra, um pouco mais adiante, Freire observa:

Nós esperamos mudar a cara da nossa escola. Não pensamos que somos os únicos, ou então os mais competentes, mas acreditamos que somos capazes e que temos a solução política para fazer isso. Nós

1 Cf. VYGOTSKI. Pensée et langage, 1985; Mesquida, Piaget e Vygotski: um diálogo inacabado, 2001. 
sonhamos com uma escola pública que seja construída progressivamente em uma arena de criatividade. Uma escola democrática na qual a pedagogia da problematização seja praticada e onde se aprende de maneira séria sem que o processo se torne em uma instrução dogmática. Uma escola que ensina conteúdo, mas também uma maneira de pensar (FREIRE, 1991, p. 24).

Freire $(1967,1973,1993)$ considera que a educação regular como uma preparação para entrar no mercado de trabalho não tem nada a ver com educação. Será que a escolarização pode ser mais do que a doutrinação institucional em um sistema social e uma cultura dominantes que reproduza, reforce e fortaleça a desvalorização de vozes silenciadas? A escolarização funciona como um instrumento que é usado para facilitar a integração da geração mais jovem na lógica do sistema capitalista de produção e para ser um elemento institucional de conformismo, como ensinava Durkheim (1973, p. 35).

Freire defende a ideia de que para, verdadeiramente educar jovens e adultos, se faz necessário um engajamento político capaz de melhorar a vida da comunidade e de realizar a mudança social e política das estruturas conservadoras e opressoras do sistema. Assim, a educação se transforma em uma prática da liberdade, o meio pelo qual homens e mulheres lidam criticamente e criativamente com a realidade e descobrem como participar ativamente da transformação do seu mundo. Colocado de outra forma, a educação é uma ação libertadora, criativa e política que possibilita a construção coletiva do conhecimento.

Por isso mesmo Paulo Freire dá ênfase a uma relação dialógica entre educador (a) e educando (a), na qual ambos aprendem e constroem o conhecimento, opondo-se ao que ele mesmo chamou de educação bancária, na qual os (as) educandos (as) são verdadeiros depósitos do conhecimento, reprodutores (as). A educação libertadora é paradoxalmente o oposto da educação bancária, pois ambas educam, uma para a manutenção do status quo de opressão, a outra para a construção comum e crítica do conhecimento que liberta. 


\section{Freire: a pedagogia da prática e a prática da pedagogia}

A obra de Freire é citada por educadores em todo o mundo e se constitui em uma importante contribuição para a pedagogia crítica, não simplesmente devido à sua sofisticação teórica, mas em particular pelo fato de Freire ter sido bem-sucedido ao colocar a teoria na prática. $\mathrm{Na}$ obra de Freire, a teoria e a prática estão solidamente conectadas e dialeticamente interligadas, produzindo uma ação pedagógica e social crítica, além de libertadora. Na concepção de um currículo, por exemplo, as ideias de Freire podem ser de suma importância, pois um currículo fermentado pelo pensamento freireano é um veículo de superação de toda e qualquer prática educativa conservadora. Por isso, Paulo Freire viu o currículo como uma estratégia pela qual educadores (as) e educandos (as) conseguem alcançar mais objetivamente fins libertadores e sociais.

Quando Freire (1976) discute a libertação, a opressão, a violência, e a liberdade, não as vê como categorias hipotéticas, mas como situações concretas nas quais ele procurou colocar suas ideias e sua teoria em prática, desde suas primeiras experiências em Recife (PE) e em Angicos $(\mathrm{RN})$, experiências pedagógicas, sociais e políticas interessantes que levaram Freire a desenvolver sua ação pedagógica nas mais diversas regiões do chamado Terceiro Mundo, ou como nós o chamamos neste artigo, Mundo da Maioria. No seu projeto de alfabetização entre os oprimidos, por exemplo com agricultores sem terra na Guiné-Bissau, ele contribuiu para a transformação de um sistema colonial opressor em um instrumento para a libertação política e cultural. Segundo Escobar e Escobar (1981), a contribuição de Freire naquela Região, incluiu a reconstrução nacional da história e do pensamento. De uma perspectiva colonial portuguesa, somente os colonizadores tinham e faziam a história, desde sua chegada "civilizatória" (ELIAS, 1994). Somente os colonizadores tinham uma cultura, uma arte, uma língua, e eram cidadãos "civilizados" que traziam a "salvação" originada do "mundo dos salvos". Os oprimidos não tinham história antes do esforço misericordioso feito pelos colonizadores; eles eram vistos como nativos bárbaros analfabetos. O trabalho de Freire na 
Guiné-Bissau, sua ação pedagógica, social e política visava, inclusive, desestabilizar as mentes fossilizadas pela ação colonizadora, mostrando que o discurso da ação civilizatória não passava de mera ideologia, isto é, de uma falsa consciência da realidade. Se na Guiné-Bissau, em outros países da África, do Norte e do Sul, bem como em países da América Latina, o método de alfabetização de Freire sofreu críticas parciais e localizadas. Isto, que foi devido muito mais à ação pedagógica conscientizadora e libertadora embutida no método do que ao próprio método, como esclarece Harasim (1983). No entanto, o método destituído da conscientização pode ser somente um conjunto de técnicas pedagógicas e alfabetizadoras.

Outra situação interessante da prática pedagógica de Freire pela qual ele tentou implementar uma reforma educacional ocorreu durante sua participação na Secretaria de Educação do Município de São Paulo, como dissemos no capítulo anterior. Em 1988, o Partido dos Trabalhadores, do qual Freire foi um dos fundadores, ganhou as eleições em São Paulo, o Município mais economicamente poderoso do Brasil. Freire foi convidado a assumir aquela Secretaria. Sua ação à frente deste importante órgão municipal durou dois anos, de 1989 a 1991. Muitos projetos ambiciosos se originaram das suas ideias, como explica Pia Lindquist Wong (1995), pesquisadora da Universidade da Califórnia, em Sacramento: a) aumento significativo do acesso à escola; b) democratização da gestão administrativa escolar; c) melhor qualidade da educação; d) aumento das oportunidades educacionais para os jovens e adultos trabalhadores; e) formação de cidadãos críticos e responsáveis. A ação de planejar a educação e o ensino à luz da sua teoria educacional levou Freire a percorrer um longo caminho antes de elaborar uma ação educativa para as escolas públicas brasileiras, no caso, as escolas do Município de São Paulo (FREIRE, 1991). Em 1989, ele criou o MOVA-SP (Movimento de Alfabetização de Jovens e Adultos da Cidade de São Paulo), no qual as bases e os movimentos sociais que atuam na alfabetização e na pós-alfabetização trabalharam em conjunto com a Secretaria Municipal de Educação.

Para Ana Maria Saul (1996), a experiência de Freire à frente da Secretaria Municipal de Educação de São Paulo, trouxe uma mudança 
expressiva no que diz respeito à concepção tradicional curricular educacional no Brasil. De uma transmissão estática, o currículo tornou-se uma prática de problematização dos contextos para educadores (as) e educandos (as). Assim, para substituir até mesmo a tradicional terminologia associada com a educação de adultos por conceitos mais apropriados, Freire substituiu a expressão "classes de alfabetização" por "círculos de cultura", nos quais os educadores e educadoras são chamados (as) de "facilitadores culturais". Ao invés de "analfabetos", Freire passou a usar o termo "relação mútua entre aprender e ensinar", ou "aprendizagem em comunhão". Ao invés de se concentrarem em alguma lição particular ou moral a ser aprendida, as pessoas da comunidade discutiam questões e preocupações comuns utilizando o seu próprio vocabulário (FREIRE, 1988). No entanto, outras matérias de outros autores sobre a experiência de Freire como formulador de políticas educacionais em São Paulo são mais reservadas do que a de Saul (TORRES, 1998, O'CADIZ et al., 1998). Podemos, assim, considerar que o sucesso de Freire foi parcial, na melhor das hipóteses. $\mathrm{Na}$ realidade, o maior desafio que Freire enfrentou durante essa experiência foi a hostilidade dos governos federal e estadual, que estavam sob o controle de outros partidos políticos historicamente hostis aos objetivos políticos e sociais de Freire e do Partido dos Trabalhadores. Acreditamos, ainda, que somado à esta hostilidade, se encontra o fato que, tanto a teoria da educação que fundamenta o método Paulo Freire de alfabetização de jovens e adultos, quanto o próprio método teriam que ser adaptados à educação escolarizada. Mesmo substituindo o termo "classes de alfabetização" por "círculos de cultura”, o espaço de ensino/aprendizagem permaneceu na escola, atrelada às normas, leis, portarias do Estado. Os círculos de cultura, espaços de educação informal, não se adaptam à formalidade da instituição escola.

Apesar da conquista parcial da implementação de seu método de alfabetização de adultos e da mitigação dos resultados, concretizando a generalização de sua abordagem no sistema escolar, sustentamos que Freire contribuiu significativamente para a reorientação do pensamento educacional na segunda metade do século XX, focado na psicologia da 
educação, para uma pedagogia mais orientada antropológica, social e politicamente, possibilitando a superação do aprendizado mnemônico, reprodutor e acrítico, e a adoção de uma prática educativa reflexiva, crítica e produtora de conhecimento novo.

$\mathrm{Na}$ abordagem freireana, a aprendizagem é exercida por um controle participativo sobre o currículo, seus métodos e conteúdos, não exclusivamente conduzida pelo progresso cognitivo trazido exclusivamente por um (a) instrutor/professor (a). Neste sentido, é claro o fato que Freire não somente postulou, mas influenciou discussões e ações concretas que promoveram mudanças radicais na pedagogia, muitas delas colocadas em prática nos mais diversos países do mundo. Dessa maneira, de um ensino por meio de uma escuta dócil e passiva, o ensino/aprendizagem torna-se uma desconstrução-reconstrução de contextos sociais. Freire destacou que os (as) educandos (as) não são receptores (as) passivos (as) do conhecimento. Não são papéis em branco (tabolae rasae) nos quais o conhecimento é impresso independentemente da sua participação reflexiva e do seu contexto social, político, cultural e econômico.

Em um livro dialogado, Freire usou uma análise desenvolvida pelo líder revolucionário africano Amilcar Cabral, o qual comenta que a distância entre a grande massa e uma minoria constituída pela elite dominante em um país colonizado, se torna cada vez maior a todo o momento. Daí a necessidade de um "suicídio de classe" da elite dominante. Assim, para não trair os objetivos de libertação, a pequena burguesia tem somente uma saída: reforçar a consciência revolucionária, lutar contra a inclinação natural de sua mentalidade de classe (FREIRE; FAUNDEZ, 1985).

Destarte, uma consciência crítica na mente dos oprimidos implica inevitavelmente a existência de uma consciência de si mesmos como uma classe social oprimida. Consequentemente, o "animador cultural" tem duas opções: contribuir diretamente com a estratégia do opressor, ou cometer suicídio como um pequeno burguês para renascer como um animador cultural com e por uma sociedade multi-cultural, na qual o silêncio não mais exista (FREIRE et al., 1997). 
Uma contribuição importante de Freire está na sua insistência em estabelecer as conexões entre teoria e prática na educação comunitária nos países do chamado Terceiro Mundo, ou como o chamamos neste artigo, Mundo da Maioria, uma ação que, em última análise, precisa ser de natureza política, como mostra a discussão de Freire sobre uma educação popular:

Em países nos quais os regimes impedem a redistribuição dos recursos sociais, a educação comunitária toma outra forma. Ela não existe por si só, mas é parte dos movimentos de base e de libertação. Ela nunca assume uma posição de passividade com relação a educação nesses movimentos; representantes de organizações de mulheres no Terceiro Mundo, por exemplo, são pessoas do povo, mas especialistas na educação de autoajuda para crianças pequenas, na criação de escolas de bairro, na formação de mulheres trabalhadoras. Nestes países a educação comunitária se desenvolveu como educação popular - utilizando conceitos que deliberadamente se diferenciam dos valores conservadores [...] (FREIRE, 1992, p. VII-VIII).

Para Freire (1991), a educação comunitária, ou educação popular, é um movimento de resistência contra falsas ideias de aprendizado, contra a preocupação da escola com os mitos que as classes dominantes, as oligarquias, os Estados de partido único e militares, difundem. A comunidade aprendente, ou a educação comunitária, tem a ver com a organização do ensino/aprendizagem a partir de baixo, visando a conexão entre o ensino/aprendizagem e a organização sócio-política dos oprimidos. Assim, aprender em comunidade, ou em comunhão, com e pelo oprimido, implica em lidar com a história da própria cultura do silêncio.

Não podemos concluir este capítulo sem apontar uma limitação fundamental no pensamento pedagógico de Freire, fazendo o que ele insistia que aqueles que trabalham com a sua teoria e a sua prática pedagógica fizessem. Freire vê dois resultados possíveis da ação pedagógica, ou seja, a "verdadeira emancipação" ou a "alienação". No entanto, sugerimos que, paradoxalmente, o aprendizado pode incluir tanto o risco de reprodução sociocultural da desigualdade quanto a possibilidade de uma transformação libertadora. A importância da linguagem no pensamento 
de Freire relacionada a este conceito de verdade, e a importância da luta de classes que permitirá aos marginalizados e reprimidos forjarem uma voz autêntica. Seria como se o conhecimento autoevidente do (a) oprimido (a) fosse menos falso do que o que seus opressores consideram válido. Ao não dar importância à linguagem dos opressores, não há o perigo dos (das) oprimidos (as) permanecerem isolados (as) do resto do mundo? Manusear o código linguístico dos opressores não é importante na luta contra a opressão? Perguntas que precisam ser respondidas. O pesquisador da Universidade de Haifa, em Israel, falecido em 2012, Ilan Gur-Ze'ev (2005), observou que Paulo Freire defende a ideia de que os interesses de todos os povos oprimidos são os mesmos, e que existe uma teoria geral para decifrar a realidade repressiva e desenvolver a potencialidade presente na memória coletiva dos oprimidos. Seria esta arma a "teoria geral" da educação freireana? Por que não?

\section{A alfabetização na teoria freireana da educação}

A alfabetização de adultos proposta por Paulo Freire está intimamente relacionada com as palavras geradoras, isto é, palavras que refletem o mundo dos educandos (as), sua vida, suas preocupações. Isso porque para Freire, ao fazer a leitura de uma palavra, de uma frase, de um texto, o educando (a) faz a leitura do contexto social que o envolve. $\mathrm{Na}$ realidade, antes mesmo de iniciar o processo de alfabetização propriamente dito, fazendo a leitura e a expressão escrita da palavra, é necessário que, pelo diálogo, se faça a leitura do mundo dos envolvidos no processo de alfabetização. A palavra instrumento da educação bancária na "boca" do opressor, vem a ser, paradoxalmente, em Freire, o logos da libertação, como ele discute na obra Educação como prática da liberdade (1967).

Do ponto de vista de Freire não há separação entre pensamento e linguagem, e a realidade na qual o alfabetizando (a) se encontra. Em outras palavras, a leitura de um texto requer fazer a leitura do contexto social, pois não é suficiente reproduzir mecanicamente e corretamente os 
sons; é necessário entender o contexto social no qual a atividade pedagógica está envolvida: entender as palavras exige a compreensão do "mundo" (FREIRE; MACEDO, 1987; GIBSON, 1994).

Inicialmente, Freire desenvolveu os conceitos de "tema gerador" e "palavra geradora" nas suas primeiras experiências em Recife. As palavras geradoras eram escolhidas com base na sua riqueza sociológica, política e fonética, constituindo-se na palavra-chave do vocabulário da pessoa, sempre relacionado a problemas concretos da sociedade e da vida, como desigualdade, justiça, fome, terra, casa, etc. Para Escobar e Escobar (1981), a palavra geradora é um caminho para conhecer, entender e intervir criticamente em uma realidade dada. Ela emerge da vida dos educandos (as) engajando-os (as) nos estudos, como um ponto de entrada para o aprendizado que tem significado e relevância para um grupo em um tempo e em um contexto específico. É a palavra que, ao se dotar de significado antropológico, social e político, produz a conscientização, dando voz aos silenciados, capacitando-os a se tornarem agentes da denúncia e do anúncio.

A partir da perspectiva de Freire, a codificação é a apresentação de uma situação existencial que está relacionada com a palavra geradora. É a apresentação de certos aspectos da realidade que gostaríamos de estudar e expressa, ainda, momentos concretos do contexto que deveriam ser vistos como um objeto de reconhecimento, ou como um símbolo do tema que está sendo discutido. Podemos dizer, enfim, que a codificação é a criação de uma representação da realidade que será analisada, ou representação de situações existenciais vividas pelos (as) aprendentes. Neste sentido, Freire observa que a codificação permite que os educandos (as) tomem distância de sua vida cotidiana, possibilitando-os perceber sua situação de uma nova maneira.

O processo de análise da codificação é chamado de decodificação, por meio do diálogo que se estabelece entre os (as) parceiros (as) do aprendizado. A decodificação é a análise que se opera através do diálogo, revelando significados despercebidos da realidade que a codificação representa. Podemos dizer que a decodificação, por meio do diálogo, é a principal ação do círculo de cultura, o elemento mais importante do processo 
de ensino/aprendizagem. Dessa maneira, para conduzir com eficiência a análise do processo de aprendizagem, Freire discute o papel dos animadores culturais, definindo com expressões, tais como libertação, domesticação do analfabeto, círculo de cultura e diálogo.

De acordo com Pia Lindquist Wong (1995), a metodologia desenvolvida em torno do conceito de temas geradores e palavras geradoras, inclui noções como crescimento individual por meio do trabalho coletivo, discussão, problematização, questionamento, conflito e participação. Assim, para Freire, segundo Lindquist Wong, o conhecimento está inserido na realidade social e precisamos nos habilitar a aplicá-lo. Outra estudiosa da obra de Freire, a professora do departamento de educação da Universidade da Califórnia, em Irvine, Maria del Pilar O'Cadiz (1998), comenta que para além da bem conhecida declaração de aprendizagem de Dewey, de que o conhecimento envolve o aprendizado por meio de uma atuação social crítica, a proposta de aprendizagem de Freire, tal como a vimos, poderia ser chamada de alfabetização sócio-política:

Os temas geradores, baseados nas situações da vida real, problemas e preocupações dos aprendizes, são usados como "tijolos" na construção do currículo localmente relevante que, ao mesmo tempo, relaciona a realidade local a uma ampla gama de problemas individuais, comunitários e sociais, como por exemplo, as relações entre pares na escola, o transporte público, a violência e a segurança pública, assim como a contaminação do ar e da água em uma cidade industrial como São Paulo (O’CADIZ et al., 1998, p. 11).

No entanto, podemos observar que, embora Freire tenha usado extensivamente o método da palavra geradora em seu trabalho, ele equilibrou uma posição que vai de uma subestimação dos métodos pedagógicos e uma superestimação de seus poderes, afirmando que os métodos são construídos e descontruídos na práxis. Por isso a necessidade de clareza sobre as opções políticas do educador (a), particularmente os valores e princípios que ele (ela) apoia e os possíveis sonhos a serem concretizados. 
Paulo Freire apresentou o seu método de alfabetização no livro Educação como prática da liberdade, publicado em 1967, o qual envolvia cinco fases:

Levantamento do universo vocabular dos grupos com quem se trabalhará; b) escolha das palavras, selecionadas do universo vocabular pesquisado; c) criação de situações existenciais típicas do grupo com quem se vai trabalhar; d) elaboração de fichas-roteiro, que auxiliem os coordenadores de debate no seu trabalho. Estas fichas-roteiro devem ser meros subsídios para os coordenadores, jamais uma prescrição rígida a que devam obedecer e seguir; e) feitura de fichas com a decomposição das famílias fonêmicas correspondentes aos vocábulos geradores (FREIRE, 1967, p. 121).

Peter McLaren (1997) observa que Paulo Freire foi um dos poucos educadores a nos levar a reconhecer os efeitos políticos da linguagem nas práticas educativas/alfabetizadoras. Freire não diz de forma clara que os agentes individuais ou coletivos que atuam na alfabetização, por exemplo, estão invariavelmente presos aos efeitos da linguagem e imobilizados politicamente por esta. A posição de Freire reflete a noção de Gramsci de que a intencionalidade estrutural dos seres humanos precisa ser criticamente examinada por meio de um processo de conscientização. Freire não aceita o mito da neutralidade política da ação alfabetizadora/ educativa, por isso mesmo os educadores (as) críticos (as) precisam levar em conta o nível de entendimento que os alfabetizandos, ao serem educados (as), têm da sua própria realidade social (FREIRE; MACEDO, 1987). Mesmo que o método de alfabetização de Freire pareça uma abordagem simplista de um problema complexo (alfabetização), ele foi um dos pilares de seu pensamento pedagógico. Um método que passou a ser adotado pelos educadores que visam a formação de uma consciência crítica capaz de colaborar significativamente para a libertação dos oprimidos, segundo o testemunho de Hilam Gur-Ze'ev (2005). 


\section{Da crítica da educação para uma educação crítica: mais um paradoxo}

Podemos afirmar, de início, que a teoria/prática de Freire representa uma importante contribuição para as pedagogias críticas e alternativas que se propõem a ser anti-hegemônicas, pedagogias que visam reduzir os efeitos das hierarquias na produção do conhecimento e atuam no sentido de resistir à ação culturalmente reprodutiva da educação institucionalizada. A rigor, as pedagogias críticas permitem a emersão de formas diferentes de conduzir o conhecimento e a aprendizagem, que se relacionam com as diferenças culturais, de classe, raciais, sexuais e de gênero, por exemplo.

Isso é possível porque a filosofia da educação de Feire tem sua gênese no envolvimento direto com a educação dos "silenciados" pelo sistema, dos "esfarrapados da terra", sendo, então, a educação um instrumento político de mudança da sua realidade; em especial pela ênfase colocada por Freire na produção coletiva do conhecimento e em uma "outra educação" que objetiva mudar a educação hegemônica do silêncio. Por este motivo, o objetivo da pedagogia crítica de Freire é dar condições aos grupos marginalizados para reconquistarem, pela palavra, suas vozes silenciadas, a fim de que possam reconhecer, identificar e nomear as coisas do mundo, fazer e refazer a história como agentes.

Podemos afirmar, à luz do que mostramos até agora, que como resultado da obra de Paulo Freire, os educadores (as) podem encontrar inspiração, bem como uma metodologia apropriada para "sonharem acordados" (BLOCH, 2005) e agirem no sentido de materializarem a utopia da realização de mudanças estruturais nas sociedades desiguais. A obra de Freire baseia-se nas considerações filosóficas, antropológicas e religiosas sobre o que significa ser humano e sobre a dimensão sócio-política da aprendizagem:

A educação de caráter libertador é um processo pelo qual o educador convida os aprendizes a reconhecerem e revelarem criticamente a realidade. A prática de domesticação tenta transmitir uma falsa consciência aos educandos, resultando em uma adaptação fácil a sua realidade; 
enquanto que a prática libertadora não pode ser reduzida a uma tentativa do educador de impor liberdade aos educandos, mas de despertar neles o desejo de conquistar a própria liberdade (FREIRE, 1985, p. 102).

Freire distingue entre a prática pedagógica que enfatiza uma educação libertadora em sociedades do Terceiro Mundo, no qual as desigualdades e as contradições são óbvias e onde a violência sofrida pela classe dominada é imediatamente observada, e ação pedagógica centrada em uma educação libertadora em uma sociedade capitalista modernizada, onde as contradições são mais veladas e na qual a manipulação da consciência é muito sofisticada. No que diz respeito ao segundo caso, o sistema educacional serviria como um poderoso instrumento de controle social (FREIRE, 1976).

Quando a educadora porto-riquenha Blanca Facundo (1984), observou que a teoria de Freire não é transferível do contexto do nordeste brasileiro para o interior do Terceiro Mundo dos Estados Unidos, ela estava indicando as limitações desta pedagogia, além de dar um exemplo de seu uso indevido. Ela levanta o fato que Freire, infelizmente, não direcionou sua atenção para questões étnicas no Brasil, nos Estados Unidos e/ ou na África, fato que, para a educação crítica, revela um limite da sua teoria. Na realidade, a pedagogia freireana não apontou as questões de raça e étnicas como elementos de opressão, nem mesmo analisando o fato de que a maioria das crianças de rua, menores em situação de criminalidade, são em grande parte descendentes de escravos. Contudo, praticamente em todos os Continentes, desde a América, passando pela África, Europa e a Austrália, educadores e educadoras, por iniciativa própria, ou com o apoio do Estado, têm seguido a teoria freireana de Educação e aplicado sua prática pedagógica em projetos de educação/alfabetização, daí o paradoxo: a teoria e a prática pedagógica de Freire estão mais presentes em programas educativos fora do Brasil do que no seu país de origem. $\mathrm{Na}$ realidade, Freire nunca afirmou fornecer aos educadores mundiais um kit pedagógico universal, pronto para ser usado em qualquer contexto.

Quando o vocábulo paradoxo aparece neste artigo, ele se apresenta a partir da etimologia da palavra grega paradoxós, que expressa a 
presença de elementos opostos em um mesmo enunciado, ou no caso, em uma mesma situação.

Ao nosso ver, seu principal legado está no fato de ter deixado pistas teóricas e metodológicas a serem empregadas de acordo com a necessidade e a relevância de cada desafio e, em especial para combater a opressão social. Para Freire, os problemas básicos da pedagogia não são estritamente pedagógicos, mas principalmente políticos e ideológicos. Acreditamos que Freire se inspirou na análise de Antonio Gamsci das sociedades contemporâneas, divididas entre os que lideram e aqueles que os seguem passivamente. Os líderes são a burguesia, os seguidores são as classes subalternas. A educação formal e a hegemonia cultural permitiram que o grupo dominante mantivesse seu poder, apesar de ser numericamente inferior aos oprimidos. De certa maneira, o exercício da hegemonia pela classe dominante levou os oprimidos a colaborarem com sua própria opressão e dominação na medida em que não lhes era permitida a tomada de consciência da situação na qual se encontravam (GRAMSCI, 1968; 1975).

Freire denunciou e atuou no sentido de realizar uma desconstrução compartilhada da educação bancária. Quando dizemos compartilhada, queremos nos referir ao fato que na ação pedagógica proposta por Freire, cada aluno tem um conhecimento legítimo, que pode ser compartilhado, como vimos na seção anterior. Afinal, estar em uma posição em que alguém é capaz de compartilhar e trocar conhecimento é algo que deve ser valorizado, pois a troca de conhecimento supera as relações superficiais estabelecidas pela educação bancária na qual a relação é vertical e monocrática. Na educação freireana educadores (as) e educandos (as) precisam conhecer, entender, ouvir e respeitar uns aos outros.

Nesse sentido, Freire (1997) insiste no fato de que a qualidade de um professor vem de sua capacidade de ouvir o educando (a): "ele ou ela que ouve o aluno com atenção e de maneira crítica é capaz de falar com o educando (a), mesmo que ocasionalmente ele/ela precise falar como educando" (p. 127-28). 


\section{Considerações finais}

A obra de Paulo Freire contém um pensamento notavelmente eclético, com contribuições do existencialismo cristão (Mounier, Marcel), de Hegel, Marx, Gramsci. Como Freire experienciou relações de poder e dominação na América Latina e em outros lugares do mundo, ele desenvolveu e praticou uma abordagem radical da educação que, atrelada a um movimento social, possibilita em regiões colonizadas a mudança social e política. Para Freire, o diálogo na educação é o princípio da liberdade. Ouvir e sentir a palavra da experiência de alguém e colocar essa experiência falada no seu devido contexto é a essência do diálogo (FREIRE, 1993). Diferente da discussão, o diálogo é caracterizado como um tipo de discurso que é humilde, aberto e focado na aprendizagem colaborativa: é a comunicação que pode despertar a consciência e preparar as pessoas para a ação coletiva. Portanto, a palavra como logos, ao se fazer presente entre os sem voz, paradoxalmente, quebra o silêncio e faz com que o silenciado tome consciência da realidade de opressão na qual está colocado, procure pela palavra da denúncia, anunciar a conquista da liberdade.

Embora as influências europeias sejam numerosas em sua obra, Freire se diferencia dos educadores ocidentais, na medida em que a sua pedagogia descoloniza o pensamento educacional contemporâneo. Em primeiro lugar, ele afasta a pedagogia dos desvios técnicos que surgiram ao longo do século XX. Insistindo no valor político da educação, Freire elabora uma pedagogia crítica adaptada ao contexto do que chamamos neste artigo de Mundo da Maioria, onde as desigualdades são mais profundas e o estado de bem-estar ausente. Mas, na obra de Freire, é difícil distinguir quando ele é pesquisador, analista, educador, assistente social ou cidadão. Todas essas identidades estão presentes ao mesmo tempo e, nesse ponto, ele se aproxima dos pedagogos e das pedagogas do Mundo da Maioria, pois sua fala e grafia são populares. Até mesmo seu estilo de escrita é particular. De fato, Freire escreve ao falar e fala enquanto escreve. Daí porque a prevalência do pensamento oral em seus livros faz com que Freire esteja disponível para o maior número de professores (as) em todo o mundo, pois ele dialoga com todos (as). É assim que sua obra não desaparece, pois 
ele constrói uma ponte entre as pedagogias dos países desenvolvidos e do Mundo da Maioria, que já se mostra aos nossos olhos, mas será ainda mais visível nas próximas décadas.

Ao falar, escreve; ao escrever fala. Esta é a grande descoberta da pedagogia de Paulo Freire enquanto pedagogia alfabetizadora: o (a) alfabetizando (a) aprende a ler enquanto escreve, e a escrever enquanto lê, tendo noção do sentido e do significado da palavra, pois a mesma nasce da sua realidade, é dialogada, refletida, significada. Por isso a palavra deixa de ser somente um som para o oprimido, para ser um grito a quebrar o silêncio que por séculos lhe foi imposto. $\mathrm{O}$ eco da palavra pode, então, se fazer liberdade.

\section{Referências}

APPLE, M. Cultural politics and education. New York: Teachers College Press, 1996.

BLOCH, E. O princípio esperança. Rio de Janeiro: Contraponto, 2005.

DARDAR, A. Culture and power in the classroom: a critical foundation for bicultural education. New York: Bergin \& Garvery, 1991.

DURKHEIM, É. Educação e sociologia. São Paulo: Melhoramentos, 1973.

ESCOBAR, H.; ESCOBAR, M. Dialogue in te pedagogical classroom práxis of Paulo Freire. Geneva: Graduate Institute of Development Studies, 1981.

ELIAS, N. O processo civilizador: uma história dos costumes. Rio de Janeiro: Zahar, 1994.

FACUNDO, B. Freire inspired programs in the United States and Puerto Rico: a critical evaluation. Washington: Latino Institute, 1984.

FREIRE, P. Educação como prática da liberdade. Rio de Janeiro: Paz e Terra, 1967.

FREIRE, P. Educational for critical consciousness. New York: The seabury Press, 1973.

FREIRE, P. L’alphabétisation et le "rêve possible" Perspectives, v. 1, p. 70-73, 1976. 
FREIRE, P. The politics oif education: culture, Power and liberation. Boston: Bergin \& Garvey, 1985.

FREIRE, P. Lettre aux agents d'éducation pour adultes. Revue Allemande d'éducation des adultes, v. 31, p. 95-100, 1988.

FREIRE, P. A educação na cidade. São Paulo: Cortez, 1991.

FREIRE, P. Forword. In: POSTER, C.; ZIMMER, J. (Eds.). Community education in the Third World. London/New York: Routledge, 1992. p. VII-VIII.

FREIRE, P. Pedagogia do oprimido. Rio de Janeiro: Paz e Terra, 1993.

FREIRE, P.; FAUNDEZ, A. Por uma pedagogia da pergunta. Rio de Janeiro: Paz e Terra, 1985.

FREIRE, P.; MACEDO, D. Literacy: reading the word and the world. London: Routledge and Kegan Paul, 1987.

GIBSON, R. The Promethean literacy: Paulo Freire's pedagogy of reading, praxis and liberation. Unpublished doctoral dissertation. Pennsylvania: The Pennsylvania State University, 1994.

GIROUX, H. Pedagogy and the politics of hope: theory, culture and schooling. Boulder: Westview Press, 1997.

GRAMSCI, A. Quaderni del cárcere. Torino: Einaudi, 1975.

GRAMSCI, A. Os intelectuais e a organização da cultura. Rio de Janeiro: Civilização Brasileira, 1968.

GUR-ZE'EV, I. Critical theory and critical pedagogy today - toward a new critical language in education. Haifa: Faculty of Education, University of Haifa, 2005.

HARASIM, L. Literacy and national reconstruction in Guinea-Bissau. A critique of the freirian literacy campaign. Unpublished doctoral dissertation. Toronto: University of Toronto, 1983.

LINDQUIST WONG, P. Construction a public popular education in Sao Paulo, Brazil. Comparative Education Review, v. 39, p. 120-141, 1995. 
LOIOLA, F.; BORGES, C. La pédagogie de Paulo Freire ou quand l'éducation devient un acte 'politique. In: TARDIF, M. La pédagogie. Théories et pratiques de l'antiquité à nos jours. Montréal: Gaëtan Morin, 1996.

MCLAREN, P. Revolutionary multiculturalism. Boulder: Westview Press, 1997.

MESQUIDA, P. Piaget e Vygotski: um diálogo inacabado. Curitiba: Ed. Champagnat, 2001. O'CADIZ, M. del P.; LINDQUIST WONG, P.; TORRES, C. A. Educação e democracia: Paulo Freire, movimentos sociais e reforma educativa. Lisboa: Edições Universitárias Lusófonas, 1998.

O'CADIZ, M.; LINDQUIST WONG, P.; TORRES, C. A. Education and democracy. Paulo Freire, social movements and educational reform in São Paulo. Boulder: Westview Press, 1998.

SAUL, A. M. Curriculo en proceso. Uma experiência en la ciudad de San Pablo - Brasil, en la gestion de Paulo Freire (1989-1992). Revista Latinoamericana de Innovaciones Educativas, v. 38, p. 35-58,1996.

VYGOTSKI, L. S. Pensée et langage. Paris: Ed. Sociales, 1985.

Recebido: 01/10/2018

Received: 10/01/2018

Recibido: 01/10/2018

Aprovado: 31/10/2018

Approved: 10/31/2018

Aprobado: 31/10/2018 